\title{
Final Remarks
}

"Decision making is only one of the tasks of an executive. It usually takes but a small fraction of his or her time. But to make the important decisions is the specific executive task. Only an executive makes such decisions" (Drucker 2001, p. 19).

Drucker's quote, which introduced the book, should also appear at the beginning of the final remarks: Drucker agrees that making decisions represents a significant - if not the most significant - task of management. Survival and long-term success depend on the correct decision.

The remarks in the book, however, have also clearly shown that decision-making represents a difficult task. Important decisions are usually complex and are therefore demanding for the actor. The authors hope that this book will help successfully overcome the analytical challenges.

However, dealing with complex problems and making the right decisions is not only an intellectual challenge. Often, much depends on the decision. Accordingly, executives are under psychological pressure. In such a situation, success is only possible for those who remain calm and are able to work systemtically. However, this book is unfortunately unable to contribute anything to solve this issue.

\section{Bibliography}

Drucker P (2001) The effective decision. In: Harvard Business School Press (Hrsg) Harvard business review on decision making. Harvard Business Press, Boston, pp 1-19 